\title{
In vitro corrosion investigations of plasma-sprayed hydroxyapatite and hydroxyapatite-calcium phosphate coatings on 316L SS
}

\author{
GURPREET SINGH ${ }^{\mathrm{a}, *}$, HAZOOR SINGH ${ }^{\mathrm{b}}$ and BUTA SINGH SIDHU ${ }^{\mathrm{c}}$ \\ ${ }^{a}$ Mechanical Engineering Department, Punjabi University, Patiala 147 002, India \\ ${ }^{b}$ Yadavindra College of Engineering, Punjabi University G.K. Campus, Talwandi Sabo 151 302, India \\ ${ }^{c}$ Punjab Technical University, Jalandhar 144 601, India
}

MS received 19 March 2013; revised 24 October 2013

\begin{abstract}
The present paper discusses various issues associated with biological corrosion of uncoated and plasma-sprayed hydroxyapatite (HA)-coated 316L SS and studies the effect of contents of calcium phosphate (CaP) on corrosion behaviour of hydroxyapatite (HA) coatings in simulated body fluid (Ringer's solution). Three types of coatings, i.e. HA + 20 wt \% CaP (type 1), HA + 10 wt\% CaP (type 2), HA (type 3), were laid on 316L SS using plasma-spraying technique. Structural characterization techniques including $\mathrm{X}$-ray diffraction (XRD), scanning electron microscopy (SEM) and energy dispersive X-ray spectroscopy (EDX) were used to investigate the crystallinity, microstructure and morphology of the coatings. Electrochemical potentiodynamic tests were performed to determine the corrosion resistance of uncoated and all the three coatings. After the electrochemical corrosion testing, the samples were examined by XRD, SEM and EDX. The electrochemical study showed a significant improvement in the corrosion resistance after HA coating and corrosion resistance of type 3 coating was found maximum.
\end{abstract}

Keywords. Hydroxyapatite (HA); calcium phosphate (CaP); corrosion; 316L SS.

\section{Introduction}

The field of biomaterials is of immense importance for mankind, apart from people with diseases, young and dynamic people like sportspersons often need replacements due to fracture and excessive strain. The first and foremost requirement for the choice of the biomaterial to be placed in the human body is that it should be biocompatible and not cause any adverse reaction in the body like allergy, inflammation and toxicity either immediately after surgery or under post-operative conditions (Fraker 1990). Second, biomaterials should possess sufficient mechanical strength and high fracture toughness to sustain the forces of high-load-bearing bones such as femoral and tibia bones, so that they do not undergo fracture (Kokubo et al 1999; Kato et al 2000). Third and most important consideration is that a bioimplant should have very high corrosion resistance because it will remain intact for a longer period in highly corrosive body environment, which includes blood and other constituents of the body fluid like water, sodium, chlorine, proteins, plasma and amino acids (Lawrence et al 1925). Moreover, corrosion can adversely affect the biocompatibility and mechanical properties of the implant.

*Author for correspondence (gurpreetsnabha@yahoo.com)
The dissolution of the surface oxide film and corrosion are the two main factors for introducing additional ions into the body that result in adverse biological reactions leading to mechanical failure of the device (Davis 2003). The composition of the surface oxide film depends on the reactions between the surfaces of metallic materials and living tissues. The dissolution of surface oxide film due to low concentration of dissolved oxygen, inorganic ions, proteins and cells can accelerate the metal ion release (Kasemo and Lausmaa 1986). So, it implies that surface oxide films existing on metallic materials play a significant part, not only for corrosion resistance but also for tissue compatibility. It is recommended to use the corrosionresistant materials or perform the coating on the implant material to keep the metal ion release at a minimum.

The corrosion resistance of the material is reduced because carbon forms carbides at the grain boundaries. So, the material with low carbon content $(<0.030 \%)$ such as 316L stainless steel is usually used for manufacturing the surgical implants (Hanawa 2002). The reason for its popularity is relative low cost, reasonable corrosion resistance, increased mechanical strength and ease of fabrication (Songur et al 2009; Manivasagam et al 2010). But, these steels are subjected to attack when they are transplanted in highly aggressive human body environment (Aksakal et al 2010). It has been reported in the literature that $70 \%$ of failures in the 316L SS are due to corrosion (Mudali et al 2003). 
So, to enhance the corrosion resistance and bonebonding ability of the implant material like biological steel and titanium, coating of bioactive materials such as hydroxyapatite $\left[\left(\mathrm{Ca}_{10}\left(\mathrm{PO}_{4}\right)_{6}(\mathrm{OH})_{2}\right), \mathrm{HA}\right]$ and calcium phosphate is performed (Furlong and Osborn 1991; Kim et al 1997; Deligianni et al 2001; Hanawa 2002). Various in vitro and in vivo studies have been carried out to check the clinical success of material for their use as surgical implants. In vitro studies are performed to give an overview of the behaviour of the material in simulated body fluid such as Hank's solution or Ringer's solution. The in vivo tests that are performed on animal models evaluate the actual performance of the materials as per the standards and guidelines approved by FDA (Food and Drug Administration, USA). Furlong and Osborn, who were the first to perform the clinical trials of HA-coated implants, have reported that HA coatings can successfully enhance clinical success. Delecrin et al (1994) have reported that calcium phosphate $(\mathrm{CaP})$ coatings promote early bone apposition at the surface of cementless orthopedic prostheses (D’Antonio et al 1996) and have given successful clinical results (Hardy et al 1994; Geesink and Hoefnagels 1995; Donnelly et al 1997; Dorr et al 1998; Hardy et al 1999; McNally et al 2000).

There are several techniques for depositing the powder on the substrate such as thermal spraying (Gross and Berndt 1998; Gross et al 1998; Li et al 2002; Chen et al 2005; Hao et al 2006; Hijon et al 2006), sputter coating (Wolke et al 2003; Yunzhi et al 2005; Thian et al 2005), pulsed laser ablation (Cleries et al 2000; Zeng and Lacefield 2000; Fernandez-Pradas et al 2001; Zhang and Cheng 2011), dynamic mixing (Yoshinari et al 1994), dip coating (Shi et al 2002; Choi et al 2003; Hijon et al 2006), sol-gel (Liu et al 2002; Manso et al 2002; Zhang et al 2007), electrophoretic deposition (Manso et al 2000; Nie et al 2001; Sena et al 2002; Ma et al 2003; Aniket and Ahmed 2011; Mihai et al 2011; Vasilescu et al 2011), biomimetic coating (Habibovic et al 2002; Adriana et al 2008), and hot isostatic pressing (Wie et al 1998). Yet plasma spray process is the most commercially, wellpreferred technique to deposit $\mathrm{HA}$ and $\mathrm{CaP}$ on metallic implants because of high deposition rate and a sufficiently low cost (Herman 1988; Ong and Chan 1999; Yang and Chang 2001; Gu et al 2002; Chen et al 2005).

In this work, atmospheric plasma spray technique was employed to spray HA-CaP coatings on 316L SS substrate. The as-sprayed coatings were characterized by X-ray diffraction (XRD), scanning electron microscopy (SEM) and energy-dispersive X-ray spectroscopy (EDX) techniques. The corrosion behaviour of uncoated, HAand HA-CaP-coated surgical steel 316L SS (L means low carbon content) in simulated body fluid (Ringer's solution) by conducting the Tafel extrapolation test has been investigated. This study is focused on the effects of adding $\mathrm{CaP}$ in HA on the corrosion resistance of HA-CaP coatings. The changes in the crystallinity and morphology of any of the exposed samples were analysed by XRD, SEM and EDX.

\section{Experimental}

\subsection{Materials}

The medical-grade $\mathrm{HA}$ and CaP powders (IFGL Bio Ceramics Limited, Kolkata, India) of 57-200 $\mu \mathrm{m}$ average particle size used as spraying materials. The mixture of $\mathrm{HA}$ and $\mathrm{CaP}$ powders in composition of $\mathrm{HA}+10 \mathrm{wt} \%$ $\mathrm{CaP}$ and $\mathrm{HA}+20$ wt $\% \mathrm{CaP}$ powders were prepared by mechanically stirring the mixture in a ceramic pot for $30 \mathrm{~min}$. Surgical steel 316L SS with chemical composition (in wt\%)-C: 0.013; Cr: 17.4; Ni: 10.8; Mo: 2.18; Si: 0.55; Mn: 0.76; P: 0.025; Cu: 0.22; and Fe: balance was used as substrate. Specimens of $316 \mathrm{~L}$ SS of size $15 \times 15 \times 3 \mathrm{~mm}$ were coated with three different types of coatings: $\mathrm{HA}+20 \mathrm{wt} \% \mathrm{CaP}$ coating (type 1), HA + $10 \mathrm{wt} \% \mathrm{CaP}$ (type 2) and HA (type 3) using plasma spray (Miller Spray System) at Anod Plasma, Kanpur, India. The substrate surface was grit-blasted with alumina of particle size $50-60 \mu \mathrm{m}$ at a pressure of 5 bar for 2 min to roughen the surface and subsequently air-blasted to remove any residual grit before spraying. Because a highly roughened substrate surface exhibited higher bond strength as compared to a smooth substrate surface (Nimb et al 1993). The plasma spray was performed at $500 \mathrm{~A}$ arc current and $50 \mathrm{~V}$ arc voltage. The argon, which is the primary gas, was supplied at 57 slpm (standard litre per minute) and the flow rate of secondary gas, hydrogen was $8 \mathrm{slpm}$. The powder was flown at $11 \mathrm{slpm}$ and the spraying distance between the plasma torch and substrate was $75 \mathrm{~mm}$.

\subsection{Characterization of coatings}

The phase structure of both feedstock powders and all the three coatings was analysed by XPERT-PRO X-ray diffractometer system. In the phase analysis, the radiation source was $\operatorname{CuK} \alpha$; the operating generator setting was $45 \mathrm{kV} / 40 \mathrm{~mA}$. The feedstock powder and coated samples were scanned over the $2 \theta$ range of $10-60^{\circ}$ and $25-50^{\circ}$, respectively. Microstructural investigation was carried out on the surfaces and polished cross sections of the coatings by SEM (EVO MA 15 ZEISS) coupled with EDX. As-sprayed coatings were cut with a low-speed precision saw at 75 rpm speed and mounted in hot resin using a hot mounting press, followed by polishing with emery papers of 220, 320, 400, 600, 800, 1000 and 2000 grades, and finally mirror finished by buffing, using an alumina slurry solution on napped cloth. To achieve the desired conductivity for observation in SEM, gold plating were performed on samples. Elemental analysis of the coatings was carried out using an EDX to investigate the $\mathrm{Ca} / \mathrm{P}$ 
ratio and to display the distribution of elements in the coatings.

\subsection{Surface roughness}

Roughness parameters such as $R_{\mathrm{a}}$ (the arithmetic mean of the departures of the roughness profile from the mean line), $R_{\mathrm{q}}$ (root mean square (RMS) of average roughness) and $R_{\mathrm{z}}$ (average of the highest peaks and the lowest valleys) are measured at five different positions on the surface of the uncoated, type 1 , type 2 and type 3 coatings on 316L SS specimens by using a roughness tester (SJ-201 MITUTOYO), with a filter of Gaussian type for a cut-off wavelength of $0.8 \mathrm{~mm}$. The average value of each parameter at various positions is reported in this study.

\subsection{Electrochemical corrosion studies}

The electrochemical corrosion behaviour of the uncoated, type 1, type 2 and type 3 coatings on 316L SS was investigated by conducting the potentiodynamic polarization tests. In a potentiodynamic scan, the potential of a metal specimen is slowly swept over a very wide potential range. During the sweep, the metal sample may undergo different electrochemical reactions, resulting in anodic and cathodic cell currents which may vary over many orders of magnitude. Potentiostat/Galvanostat (Series G-750; Gamry Instruments, Inc, USA), interfaced with a personal computer installed with specific Gamry electrochemical software 'DC105', was used to conduct the test. Ringer's solution (Nice Chemical Pvt. Ltd., Cochin, India) with chemical composition (in $\mathrm{g} / \mathrm{L}$ ) as 9 $\mathrm{NaCl}, 0.24 \mathrm{CaC}_{12}, 0.43 \mathrm{KCl}$ and $0.2 \mathrm{NaHCO}_{3}$ at $\mathrm{pH} 7.2$ was used as the electrolyte for simulating human body fluid conditions. The 316L SS specimen forms the working electrode. All the potentials were measured with respect to the saturated calomel electrode (SCE) as reference electrode. A graphite rod served as the counter electrode. The instrument measures and controls the potential difference between a non-current-carrying reference electrode and one of the two current-carrying electrodes (the working electrode). All tests were performed at a scan rate of $1 \mathrm{mV} / \mathrm{s}$ and fresh solution was used for each experiment. Polarization curves were initiated at -250 to $+250 \mathrm{mV}$ relative to open circuit potential. The initial delay of $24 \mathrm{~h}$ is given for the stabilization of immersed specimen in Ringer's solution.

\section{Results and discussion}

\subsection{XRD analysis}

The feedstock powders (HA and $\mathrm{CaP}$ ) and all the three coated samples were scanned over the $2 \theta$ range of $10-60^{\circ}$ and $25-50^{\circ}$, respectively. The XRD patterns of HA powder (figure 1) and $\mathrm{CaP}$ powder (figure 2) are composed of crystalline phases. All the major peaks belong to HA and CaP matches the JCPDS cards 74-566 and 70-364, respectively. XRD patterns of plasma-sprayed type 1, type 2 and type 3 plasma coating on 316L are shown in figure 3 . The structure of all the coatings is crystalline. However, the degree of crystallinity is increasing and the peaks became sharper and less broadened as the presence of calcium phosphate content increased. The rise in peaks of type 1 and type 2 has been noticed in the range of $20^{\circ} 2 \theta-25^{\circ} 2 \theta$.

\subsection{SEM/EDX analyses}

3.2a Surface analysis: The morphology of HA and $\mathrm{CaP}$ powders (figure 4 ) confirms that the HA powder has the spherical shape and CaP powder has the angular and irregular shape. The size distribution range in both the powders seems to be wider. It is worthwhile to mention

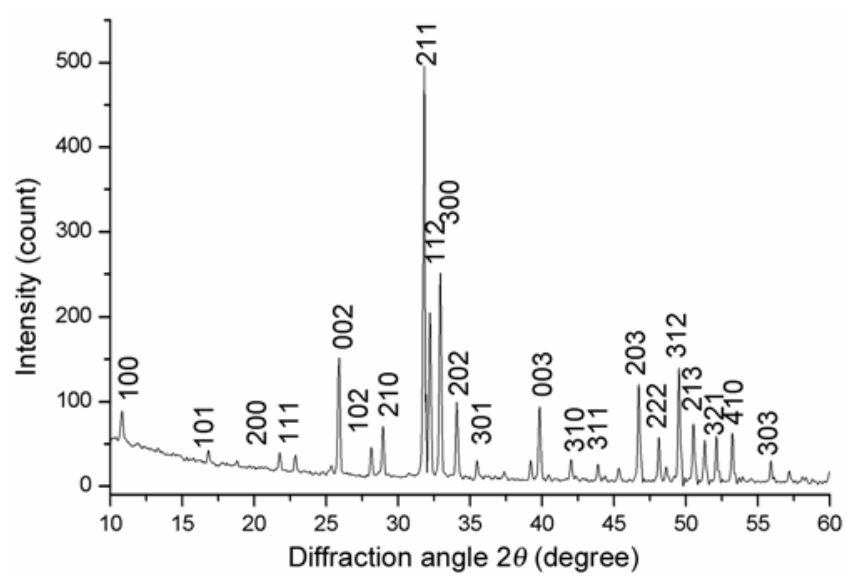

Figure 1. X-ray diffraction patterns of HA powder.

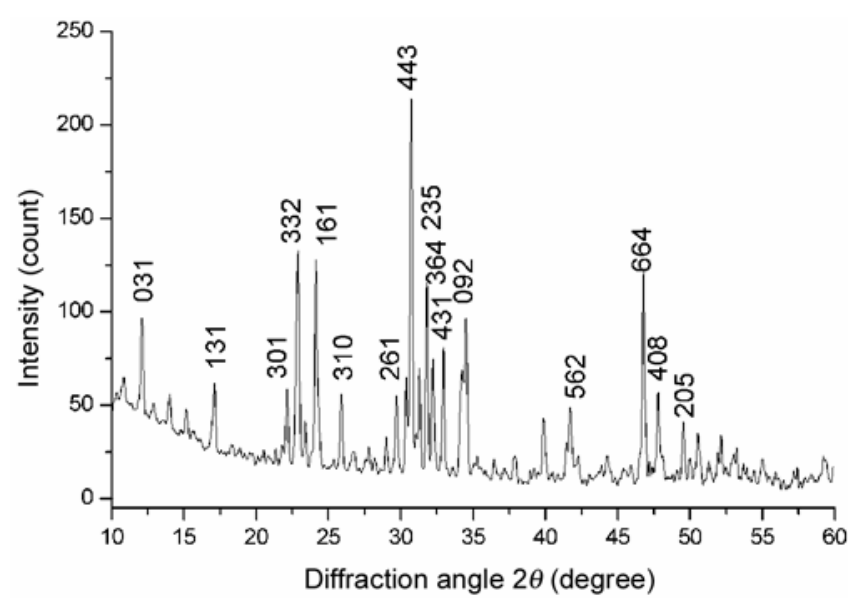

Figure 2. X-ray diffraction patterns of CaP powder. 
that the particles size and shape influence the final microstructure of the plasma-spray coating. The morphology and elemental compositions of the surface of type 1, type 2 and type 3 coatings on 316L substrate is investigated by SEM and EDX analyses. SEM micrograph at the surface of type 1 coating (figure $5 a$ ) shows the microstructure that consists of well-formed interconnected splats of HA particles with uneven surface. Some voids or pores can also be observed but no microcracks were observed on the coating. The EDX analysis shows the presence of calcium (Ca), phosphorous (P), carbon (C) and oxygen (O) elements, which were main components of HA powder. The average $\mathrm{Ca} / \mathrm{P}$ ratio was $1 \cdot 6$, which lies in between the guidelines described by the Food and Drug Administration and the ISO standards (FDA 1992; ISO 1996).

SEM micrograph of type 2 coating (figure $5 \mathrm{~b}$ ) shows that the microstructure consist of molten splats which are fused to each other due to the presence of irregular-shaped $\mathrm{CaP}$ particles. The coating surface was uneven and some voids were observed, which were less when compared to the type 1 coating. The microstructure of type 3 coatings (figure 5c) appears to be denser and smoother as compared to type 1 and type 2 coatings because of the absence of irregular-shaped $\mathrm{CaP}$ particles that lead to the rise in the flattening ratio of the melting particles. It is generally believed that if the density of coating surface is higher then the corrosion resistance of the surface is

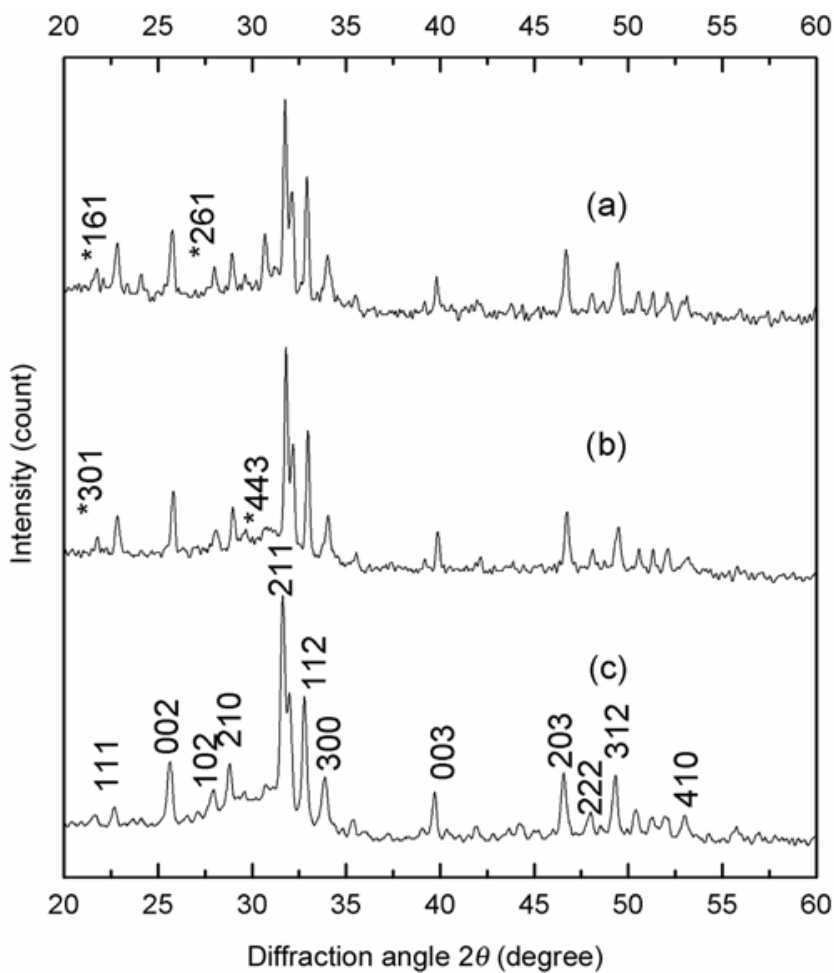

Figure 3. X-ray diffraction pattern of: (a) HA + $20 \mathrm{wt} \% \mathrm{CaP}$ (type 1), (b) HA + $10 \mathrm{wt} \%$ CaP (type 2) and (c) HA (type 3) as-sprayed plasma coatings on 316L SS. more. The EDX analysis at three different positions indicates the presence of $\mathrm{Ca}, \mathrm{P}$ and $\mathrm{O}$. The average value of the $\mathrm{Ca} / \mathrm{P}$ ratio in type 1 and type 2 coatings were also increased but will remain in agreement with the standard results (FDA 1992; ISO 1996).

3.2b Cross-sectional analysis: The characterization of plasma-sprayed type 1 , type 2 and type 3 coatings at cross section is performed by SEM and EDX analyses and is shown in figure 6 . The average thickness of all the coatings is $100 \pm 20 \mu \mathrm{m}$. All the coatings show good bond with the substrate. The type 1 and type 2 coatings (figure 6a,b) have significant presence of pores. The analysis reveals that type 1 coating (figure $6 \mathrm{c}$ ) appears to be denser and smoother. The EDX analysis showed peaks of calcium and phosphor are longer in type 1 coating in comparison with type 2 and type 3 coatings, because of the mixing of $\mathrm{CaP}$ in the $\mathrm{HA}$ used as feedstock powder. The increase in proportion of $\mathrm{CaP}$ promotes osteoconduction, while HA particles carry the biological apatite precipitation (Daculsi et al 1989). It has been reported in
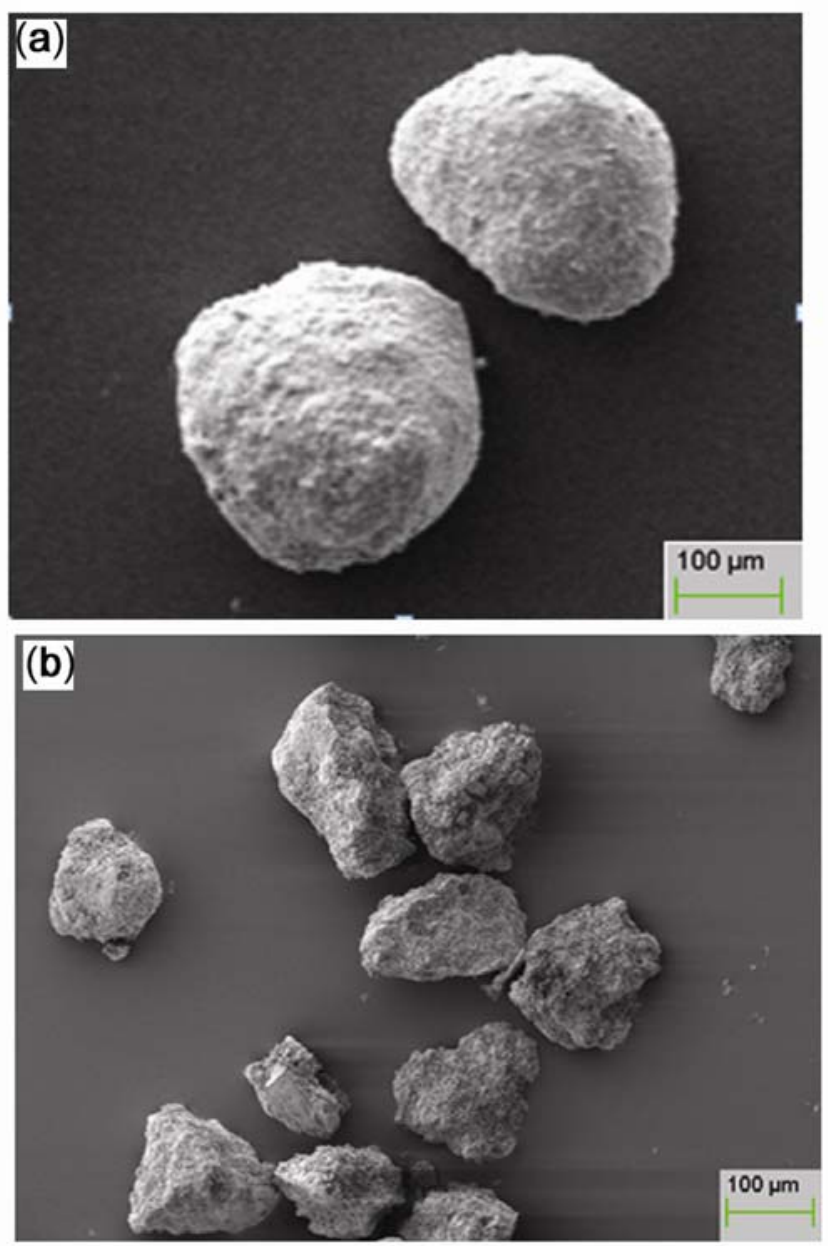

Figure 4. SEM micrograph of (a) HA powder and (b) CaP powder. 


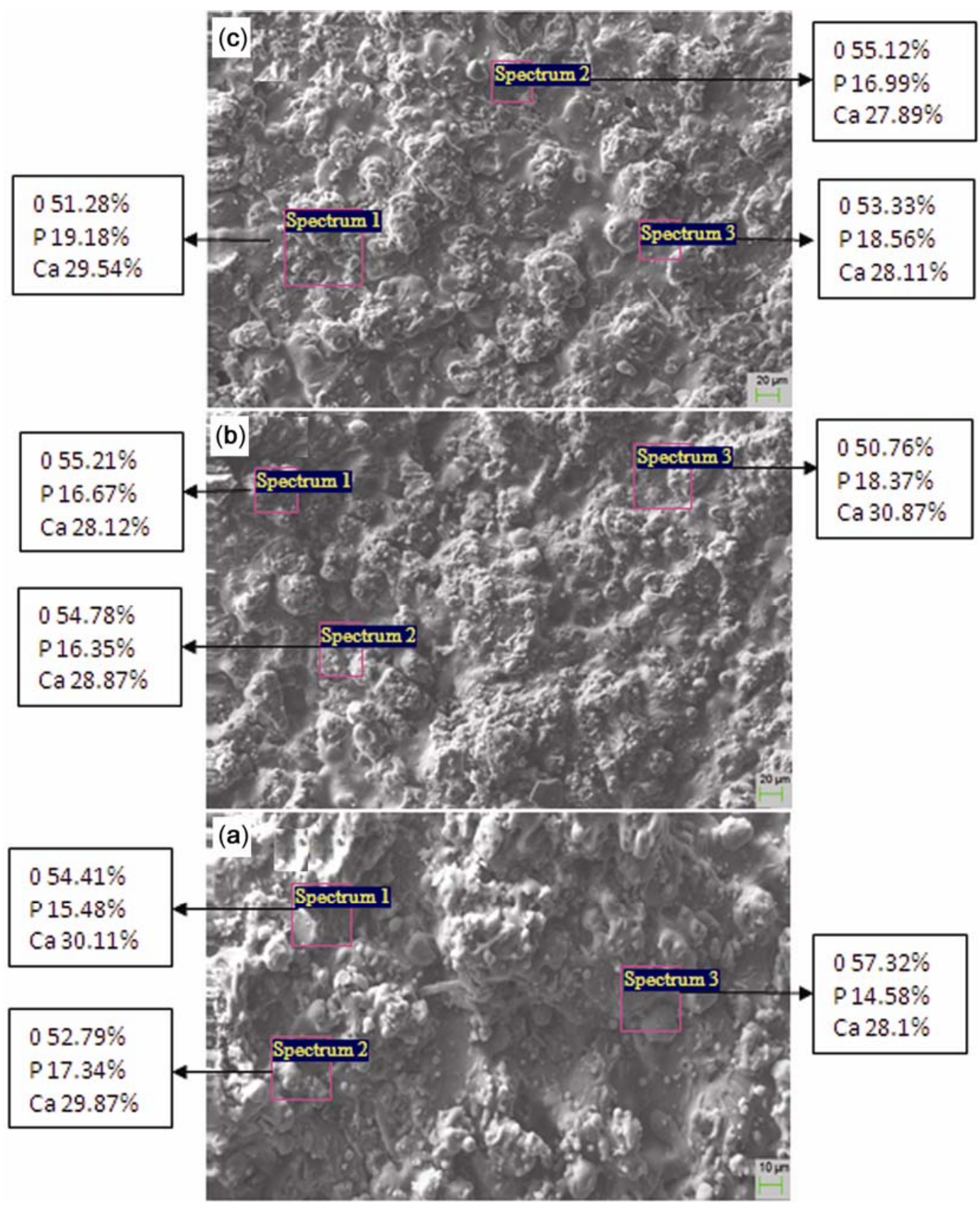

Figure 5. SEM micrograph and EDX analysis at the surface of (a) HA $+20 \mathrm{wt} \% \mathrm{CaP}$ (type 1), (b) $\mathrm{HA}+10 \mathrm{wt} \% \mathrm{CaP}$ (type 2) and (c) HA (type 3) as-sprayed plasma coatings on 316L SS (*represents the $h k l$ indexing of CaP and other represents $h k l$ indexing of $\mathrm{HA}$ ).

literature that highly soluble coatings are more osteoconductive and bioactive in comparison to the stable layers in vivo (Dhert et al 1993). The osteointegration of CaP coatings is faster than of HA coatings in non-load-bearing conditions (Delecrin et al 1994).

\subsection{Surface roughness}

The implant tissue interaction and the biocompatibility in clinical use have been greatly affected by surface rough- ness, surface topography, surface energy and chemical composition, as reported in literature (Schwartz and Boyan 1994; Lee et al 2002). High surface roughness will increase the coating and body-fluid interface, and thus increase the dissolution rate and apatite precipitation (Sun et al 2001). The surface roughness parameters $\left(R_{\mathrm{a}}, R_{\mathrm{q}}\right.$, and $R_{\mathrm{z}}$ ) for uncoated, type 1 , type 2 and type 3 plasma coatings on 316L SS are shown in table 1 . The average surface roughness $\left(R_{\mathrm{a}}\right)$ value for uncoated, type 1 , type 2 and type 3 plasma coatings on 316L SS are 

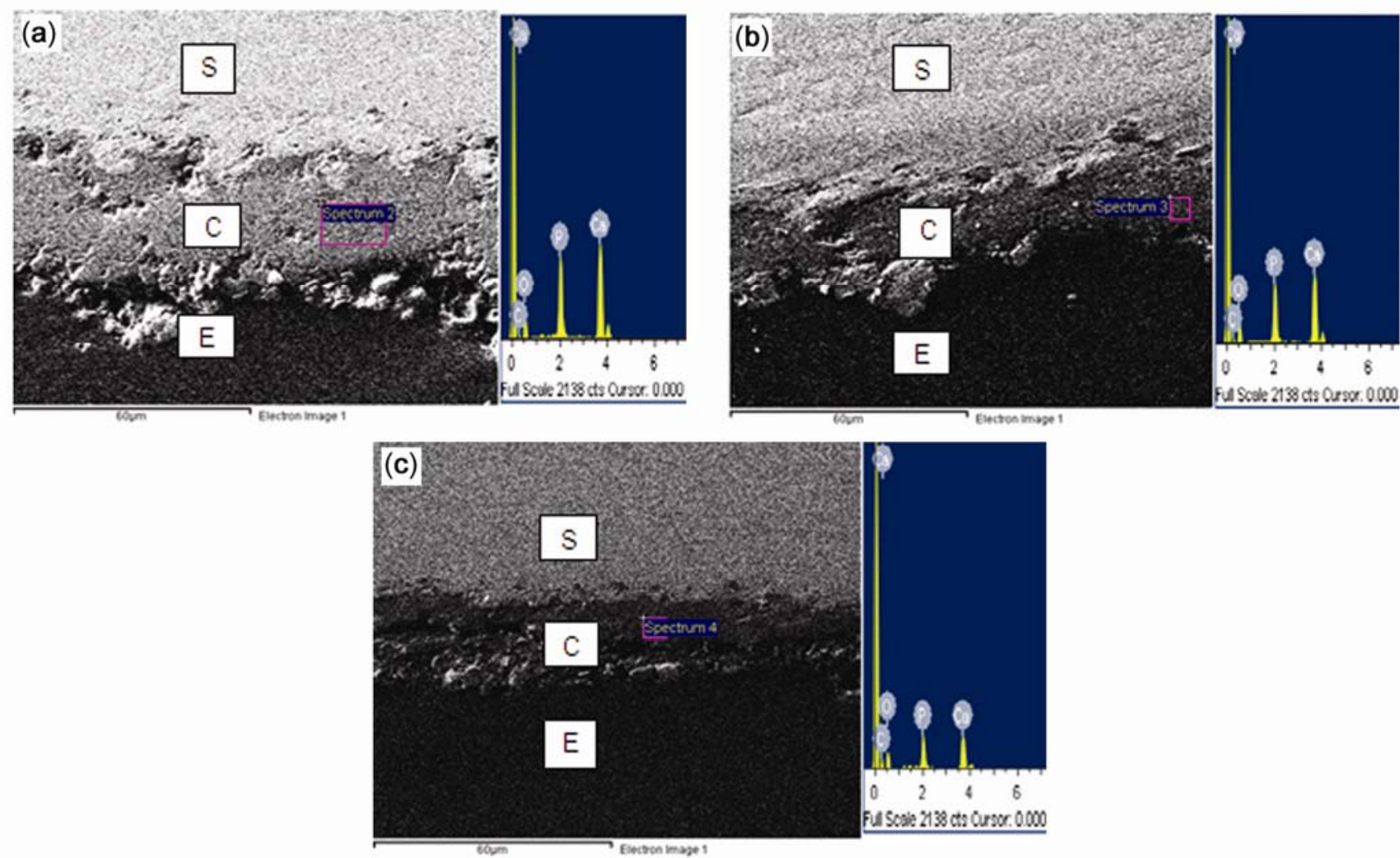

Figure 6. SEM and EDX along the cross section of plasma-sprayed (a) HA + 20 wt\% CaP (type 1), (b) HA + 10 wt $\%$ CaP (type 2) and (c) HA (type 3) as-sprayed plasma coatings on 316L SS (S, C, E represent the substrate, coating and epoxy, respectively).

Table 1. Roughness values of uncoated 316L SS, type 1, type 2 and type 3 plasma coatings on 316L SS.

\begin{tabular}{lcccc}
\hline Parameter & Uncoated & Type 1 coating & Type 2 coating & Type 3 coating \\
\hline$R_{\mathrm{a}}$ & $0 \cdot 764$ & $7 \cdot 2$ & $6 \cdot 904$ & $5 \cdot 584$ \\
$R_{\mathrm{z}}$ & $4 \cdot 129$ & $40 \cdot 132$ & $36 \cdot 79$ & $38 \cdot 628$ \\
$R_{\mathrm{q}}$ & 0.968 & $8 \cdot 776$ & $8 \cdot 386$ & $7 \cdot 186$ \\
\hline
\end{tabular}

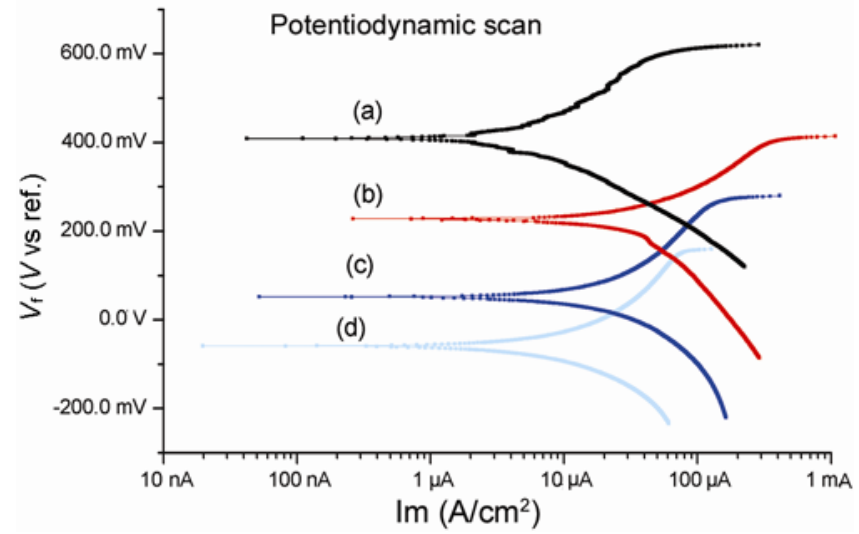

Figure 7. Potentiodynamic curves of (a) uncoated, (b) $\mathrm{HA}+20 \mathrm{wt} \% \mathrm{CaP}$ (type 1), (c) HA + $10 \mathrm{wt} \% \mathrm{CaP}$ (type 2) and (d) HA (type 3) coatings on 316L SS during $24 \mathrm{~h}$ immersion in Ringer's solution.
$0 \cdot 764 \pm 0 \cdot 2, \quad 7 \cdot 2 \pm 0 \cdot 4, \quad 6 \cdot 904 \pm 0.4$ and $5.584 \pm 0.4 \mu \mathrm{m}$, respectively.

Gross and Babovic (2002) reported that plasma-sprayed coating with a powder particle size of $20-30 \mu \mathrm{m}$ gives a surface roughness of $4-6 \mu \mathrm{m}$. The surface roughness of type 3 coating is in agreement, as reported by Gross and Babovic, but the surface roughness of the type 1 and type 2 coatings is just more than $6 \mu \mathrm{m}$ as the powder particles size is more in this work. Plasma-spray technique is well known for creating HA- and CaP-coated surface composed of rough and smooth areas. The un-melted particles produce rough areas within and on the surface of the coating. Crystalline particles spread over the coating surface when the un-molten particle core is not sufficiently strong to fragment upon impact with the substrate (Gross and Babovic 2002). The smooth areas in the coating are the result of melting of the powder. 
Table 2. Corrosion parameters determined by the tafel extrapolation test.

\begin{tabular}{lcccc}
\hline Parameter & Uncoated & Type 1 coating & Type 2 coating & Type 3 coating \\
\hline$\beta_{\mathrm{a}}, e^{-3}$ V/decade & $197 \cdot 3$ & 41.10 & $117 \cdot 8$ & 157.7 \\
$\beta_{\mathrm{c}}, e^{-3} \mathrm{~V} /$ decade & 339.5 & 63.30 & 811.5 & 124.7 \\
$E_{\text {Corr }}, \mathrm{mV}$ & -73.10 & -93.60 & -87.90 & -59.0 \\
$I_{\text {Corr }}, \mu \mathrm{A}$ & 2.950 & 1.160 & 1.130 & 1.09 \\
\hline
\end{tabular}

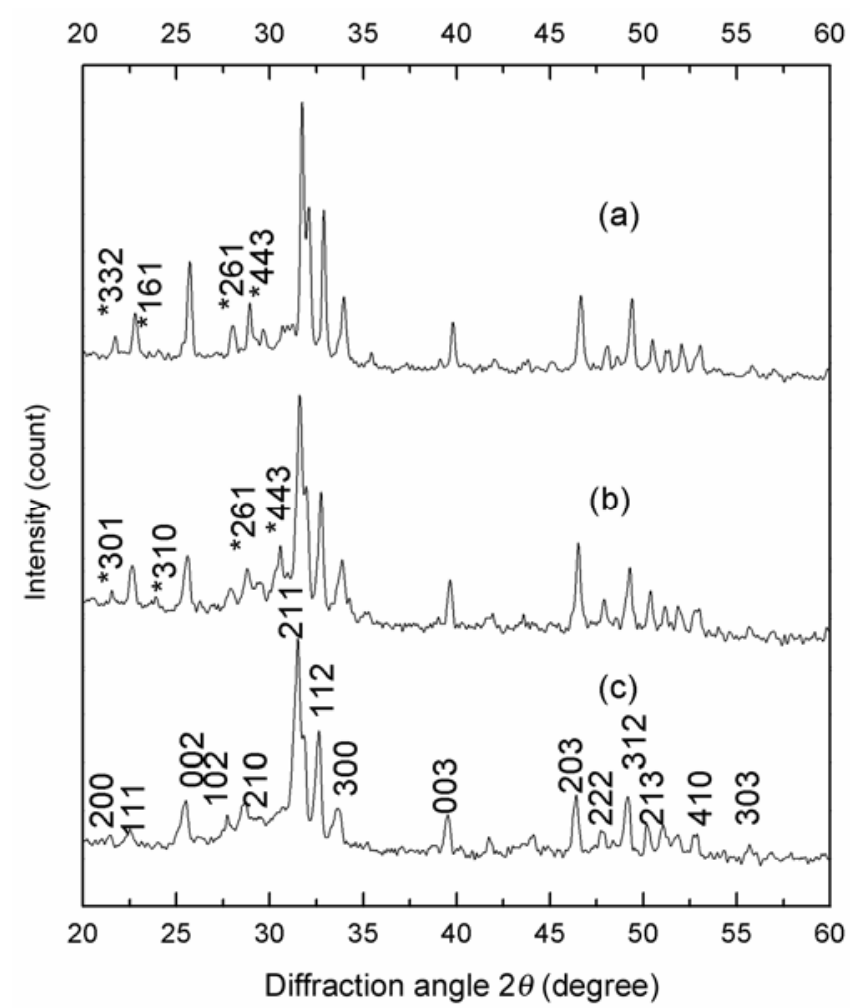

Figure 8. X-ray diffraction pattern of (a) HA $+20 \mathrm{wt} \% \mathrm{CaP}$ (type 1), (b) HA + $10 \mathrm{wt} \% \mathrm{CaP}$ (type 2) and (c) HA (type 3) coatings on 316L SS after $24 \mathrm{~h}$ immersion in Ringer's solution (* represents the $h k l$ indexing of $\mathrm{CaP}$ and other represents $h k l$ indexing of HA).

\subsection{Corrosion behaviour}

The potentiodynamic scans of the uncoated, type 1, type 2 and type 3 coatings on 316L samples in Ringer's solution are shown in figure 7 . The corrosion parameters such as anodic tafel slope $\left(\beta_{\mathrm{a}}\right)$, cathodic tafel slope $\left(\beta_{\mathrm{c}}\right)$, corrosion potential $\left(E_{\text {Corr }}\right)$ and corrosion current density $\left(I_{\text {Corr }}\right)$ are determined from the potentiodynamic curves by conducting the tafel extrapolation test. The results of these corrosion parameters are shown in table 2 . The chance of corrosion in a material depends upon the corrosion current density $\left(I_{\text {Corr }}\right)$ at a given potential, material will be more corrosion resistant at a lower value of $I_{\text {Corr }}$ (Songur et al 2009; Aksakal et al 2010; Manivasagam et al 2010).

The result of tafel-slope values shows that corrosion current density of type $3\left(I_{\text {Corr }}=1.09 \mu \mathrm{A}, E_{\text {Corr }}=-59 \mathrm{mV}\right)$ coating in Ringer's solution is less than the plasmasprayed type $2\left(I_{\text {Corr }}=1.130 \mu \mathrm{A}, E_{\text {Corr }}=-87.90 \mathrm{mV}\right)$ and type $1\left(I_{\text {Corr }}=1.160 \mu \mathrm{A}, E_{\text {Corr }}=-93.60 \mathrm{mV}\right)$ coating on 316L SS, whereas the corrosion current density of uncoated 316L SS sample in Ringer's solution is $\left(I_{\text {Corr }}=\right.$ $2.950 \mu \mathrm{A}, E_{\text {Corr }}=-73.10 \mathrm{mV}$ ) highest.

So the analysis of tafel-slope values indicates that the type 3 coating on 316L SS with lowest $I_{\text {Corr }}$ values is the most corrosion-resistant specimen among the uncoated, type 1 and type 2 coated 316L SS specimens in Ringer's solution. The results also suggest that the increase in percentage of $\mathrm{CaP}$ in $\mathrm{HA}$ also decreases the corrosion resistance of plasma coating 316L SS. The results are in agreement with the previous studies conducted by Singh et al 2012, 2013).

After electrochemical corrosion testing in Ringer's solution, the XRD scans of type 1 (figure 8a), type 2 (figure 8b) and type 3 (figure 8c) coatings show interesting behaviour. All the coatings appeared more crystalline and the intensity of XRD peaks were found to be increased. The sharp peaks after immersion indicate the dissolution of the amorphous phases (Sousa and Barbosa 1996). It is reported that amorphous phases are more soluble than crystalline HA, as they encourage the early bone growth (Maxian et al 1993). The dissolution was favourable for the early stages of transformation of biological equivalents that act as a mediator between osteoclast and osteoblast differentiation (Xue et al 2004). The higher-crystalline coating leads to longer implant life, while some implant manufacturers prefer a fasterdissolving coating to enhance bone growth (Gross and Saber-Samandari 2007). It has been reported in in vivo studies that the phase purity, crystallinity and microstructure of HA coatings affect the biological response of HA coating (Yang et al 1997). The crystallinity of the coating leads to different dissolution rates in vivo. It had been reported in literature that the crystalline HA coatings showed minor signs of degradation, whereas an amorphous HA coating completely disappeared after 24 weeks in goat femurs (Clemens et al 1998).

The microstructural investigations on the surfaces of the exposed specimens were examined by SEM and EDX. The morphology of type 1 and type 2 coatings (figure 9(a and b)) changes to flattened particles and looks smooth and denser after exposure to the corrosion testing in Ringer's solution. A comparison of SEM micrographs of the as-sprayed type 3 (figure $5 \mathrm{a}$ ) and exposed type 3 coating (figure 9c) shows that the coating had retained its 


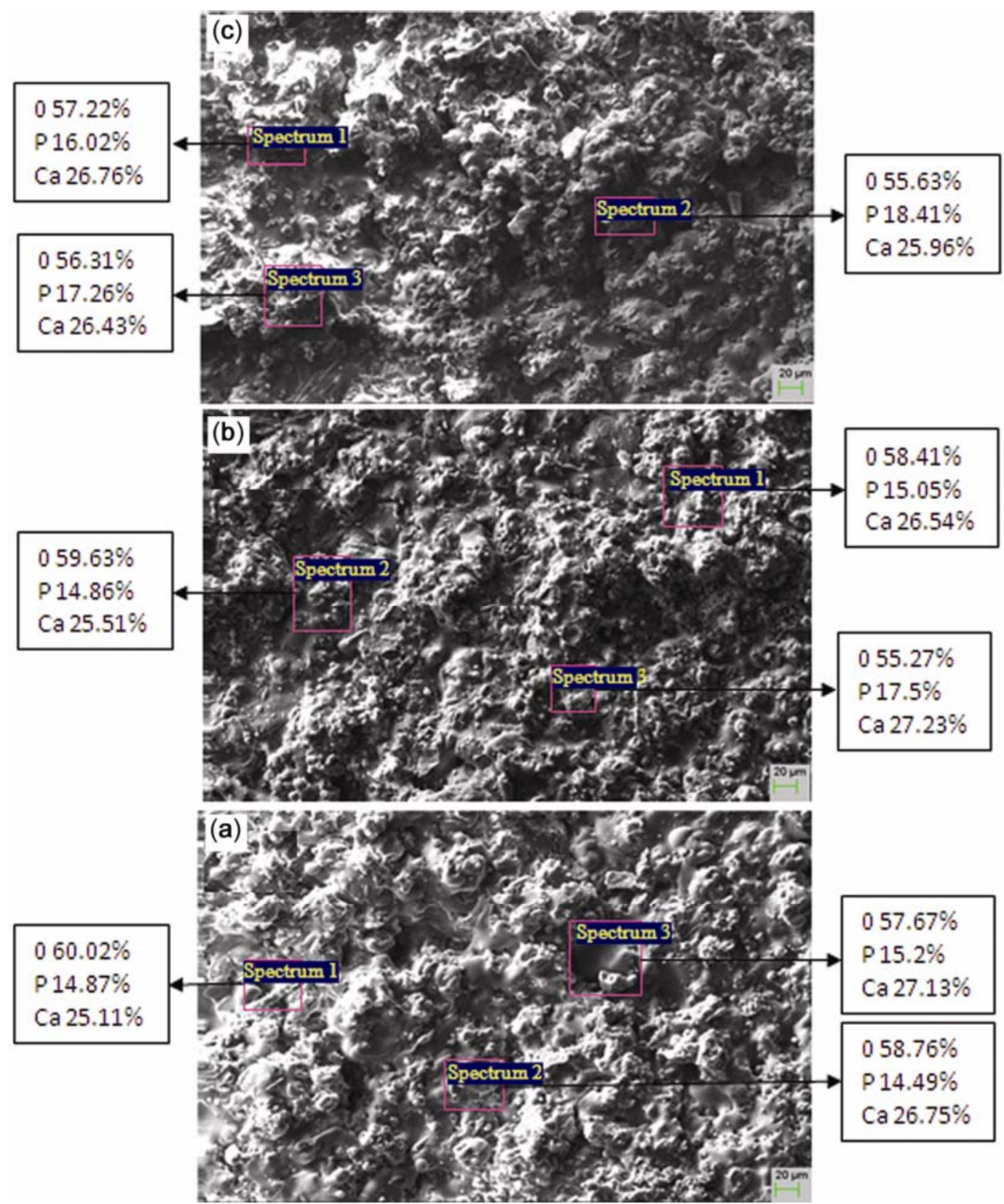

Figure 9. SEM micrograph and EDX analysis at the surface of (a) HA + $20 \mathrm{wt} \% \mathrm{CaP}$ (type 1), (b) $\mathrm{HA}+10 \mathrm{wt} \% \mathrm{CaP}$ (type 2) and (c) HA (type 3) coatings on 316L SS after $24 \mathrm{~h}$ immersion in Ringer's solution.

morphology even after exposure to the corrosion testing. No cracks were found on both the Ha- and HA-CaPcoated exposed specimens.

EDX analysis confirms the presence of $\mathrm{Ca}, \mathrm{P}$ and $\mathrm{O}$ elements in all coatings. EDX analyses of exposed specimens show that $\mathrm{Ca}$ and $\mathrm{P}$ (at\%) decrease by taking the average of elemental composition at three spectra after $24 \mathrm{~h}$ immersion in Ringer's solution. The decrease in the values indicates that phosphate accumulates on the surface, which suggests that incongruent dissolution of the HA has taken place (Sousa and Barbosa 1996). No constituent of substrate such as $\mathrm{Cr}, \mathrm{Ni}$ and Mo was found on the surface of any coatings after immersion for $24 \mathrm{~h}$ in Ringer's solution.

\section{Conclusions}

In the present study, plasma-spray technique was used to deposit the HA + $20 \mathrm{wt} \% \mathrm{CaP}$ (type 1), HA + $10 \mathrm{wt} \%$ CaP (type 2) and HA (type 3) coatings on 316L SS. The plasma-sprayed type 3 and type 2 coatings are more crystalline than type 1 coating on 316L SS. The plasma-sprayed 
type 1 and type 2 coatings exhibited higher surface roughness than type 3 coating on 316L SS. The electrochemical study showed the corrosion resistance of the 316L SS increased after the deposition of plasma-sprayed type 3 coating compared to uncoated, type 1 and type 2 plasma-sprayed coatings on 316L SS in Ringer's solution. A comparison of the SEM micrographs of both plasma-sprayed coatings before and after corrosion testing in Ringer's solution showed that HA coating retains its morphology, whereas the morphology of HA + $20 \mathrm{wt} \%$ $\mathrm{CaP}$ and $\mathrm{HA}+10 \mathrm{wt} \% \mathrm{CaP}$ coatings changes to flattened particles and looks smoother and denser after exposure to the corrosion testing in Ringer's solution. No cracks were found on any coated exposed specimens.

Future in vivo studies of plasma-sprayed type 1, type 2 and type 3 coatings on 316L SS and a complete interpretation of these results can help in assessing their use in clinical applications.

\section{References}

Adriana Bigi, Milena Fini, Barbara Bracci, Elisa Boanini, Paola Torricelli, Gianluca Giavaresi, Nicolo N, Aldini Alessandro, Facchini Fausto Sbaiz and Roberto Giardino 2008 Biomaterials 291730

Aksakal B, Gavgali M and Dikici B 2010 J. Mater. Eng. Perform. 19894

Aniket and Ahmed El-Ghannam 2011 J. Biomed. Mater. Res. Part B: Appl. Biomater. B99 369

Chen C, Wang D, Bao Q, Zhang L and Lei T 2005 Appl. Surf. Sci. 25098

Choi J, Bogdanski D, Koller M, Esenwein S A, Muller D, Muhr G and Epple M 2003 Biomaterials 243689

Cleries L, Martinez E, Fernandez-Pradas J M, Sardin G, Esteve J and Morenza J L 2000 Biomaterials 21967

Clemens J A, Klein C P, Vriesde R C, Rozing P M and Groot K D 1998 J. Biomed. Mater. Res. 3341

D’Antonio J A, Capello W N and Manley M T 1996 J. Bone Jt. Surg. Am. 81226

Daculsi G, LeGeros R Z, Nery E, Lynch K and Kerebel B 1989 J. Biomed. Mater. Res. 8883

Davis J R 2003 Handbook of materials for medical devices (ASM International)

Delecrin J, Daculsi G, Passuti N and Duquet B 1994 Cells Mater. 151

Deligianni D D, Katsala N D, Koutsoukos P G and Missirlis Y F 2001 Biomaterials 2287

Dhert W J, Klein C P, Jansen J A, Van der Velde E A, Vriesde R C and Rozing P M 1993 J. Biomed. Mater. Res. 27127

Donnelly W J, Kobayashi A, Freeman M A, Chin T W, Yeo H and West M 1997 J. Bone Jt. Surg. Br. 3351

Dorr L D, Wan Z, Song M and Ranawat A 1998 J. Arthroplasty 7729

FDA 1992 Calcium phosphate (Ca-P) coating draft guidance for preparation of FDA submissions for orthopedic and dental endosseous implants (Washington DC Food and Drug Administration) p. 1

Fernandez-Pradas J M, Cleries L, Martinez E, Sardin G, Esteve J and Morenza J L 2001 Biomaterials 222171
Fraker A C 1992 Corrosion ASM handbook (ASM International) vol. 13, p. 1324

Furlong R J and Osborn J F 1991 J. Bone. Jt. Surg. B73 741

Geesink R G and Hoefnagels N H 1995 J. Bone. Jt. Surg. Br. 4534

Gross K A and Babovic M 2002 Biomaterials 234731

Gross K A and Saber-Samandari S 2007 J. Aust. Ceram. Soc. 4398

Gross K A and Berndt C C 1998 J. Biomed. Mater. Res. 39580

Gross K A, Berndt C C and Herman H 1998 J. Biomed. Mater. Res. 39407

Gu Y W, Loh N H, Khor K A, Tor S B and Cheang P 2002 Biomaterials 2337

Habibovic P, Barrere F, Van Bliterswijk De C A, Groot K and Layrolle P 2002 J. Am. Ceram. Soc. 85517

Hanawa T 2002 J. Artif. Organs 1273

Hao Wang, Noam Eliaz, Zhou, Xiangc Hu-Ping and Hsuc Myron 2006 Biomaterials 274192

Hardy D C, Frayssinet P, Bonel G, Authom T, Naelou Le and Delince S A PE 1994 Acta Orthop. Scand. 3253

Hardy D C, Frayssinet P, Krallis P, Descamps P Y, Fabeck L and Delplancke J L 1999 Acta Orthop. Belg. 172

Herman H 1988 MRS Bull. 1260

Hijon N, Victoria Cabanas M, Juan Pena and Vallet Regi Maria 2006 Acta Biomater. 2567

ISO 1996 Implants for surgery: coating for hydroxyapatite ceramics (ISO) p. 1

Kasemo B and Lausmaa J 1986 CRC Crit. Rev. Biocompat. 2 335

Kato H, Nakamura T, Nishiguchi S, Matsusue Y, Kobayashi M, Miyazaki T, Kim H M and Kokubo T 2000 J. Biomed. Mater. Res. 5328

Kim H M, Miyaji F, Kokubo T and Nakamura T 1997 J. Biomed. Mater. Res. 38121

Kokubo T, Miyaji F and Kim H M 1999 J. Am. Ceram. Soc. 79 1127

Lawrence S K, Gertrude M and Shults 1925 J. Exp. Med. 42 565

Lee T M, Tsai R S, Chang E, Yang C Y and Yang M R 2002 J. Mater. Sci.: Mater. Med. 13341

Li H, Khor K A and Cheang P 2002 Biomaterials 2385

Liu D, Yang Q and Troczynski T 200223691

Ma J, Wang C and Peng K W 2003 Biomaterials 243505

Manivasagam G, Dhinasekaran D and Rajamanickam A 2010 Recent Pat. Corros. Sci. 240

Manso M, Jimenez C, Morant C, Herrero P and Martinez-Duart J M 2000 Biomaterials 211755

Manso M, Langlet M, Jimenez C and Martinez-Duart J M 2002 Biomol. Eng. 1963

Maxian S H, Zawadsky J P and Dunn M G 1993 J. Biomed. Mater. Res. 27717

McNally S A, Shepperd J A, Mann C V and Walczak J P 2000 J. Bone Jt. Surg. Br. 3378

Mihai V Popa, Jose Maria Calderon Moreno, Monica Popa, Ecaterina Vasilescu, Paula Drob, Cora Vasilescu and Silviu I Drob 2011 Surf. Coat. Technol. 204776

Mudali U K, Sridhar T M and Raj B 2003 Sadhana 28601

Nie X, Leyland A, Matthews A, Jiang J C and Meletis E I 2001 J. Biomed. Mater. Res. 57612

Nimb L, Gotfredsen K and Steen J J 1993 Acta Orthop. Belg. $\mathbf{5 9} 333$ 
Ong J L and Chan C N 1999 Crit. Rev. Biomed. Eng. 28 667

Schwartz Z and Boyan B D 1994 J. Cell. Biochem. 56340

Sena D E LA, Andrade D E MC, Rossi A M and Soares G D A 2002 J. Biomed. Mater. Res. 601

Shi D, Jiang G and Bauer J 2002 J. Biomed. Mater. Res. (Appl. Biomater.) 6371

Singh G, Singh H and Sidhu B S 2013 Surf. Coat. Technol. 228 242

Singh T P, Singh H and Singh H 2012 J. Therm. Spray Technol. (doi: 10.1007/s11666-012-9782-x)

Songur M, Celikkan H, Gokmese F, Simsek S A, Altun N S and Aksu M L 2009 J. Appl. Electrochem. 391259

Sousa S R and Barbosa M A 1996 Biomaterials 17397

Sun L, Berndt C C, Gross K A and Kucuk A 2001 J. Biomed. Mater. Res. (Appl. Biomater.) 58570

Thian E S, Huang J, Best S M, Barber Z H and Bonfield W 2005 Biomaterials 262947
Vasilescu C, Drob P, Vasilescu E, Demetrescu I, Ionita D, Prodana M and Drob S I 2011 Corr. Sci. 53992

Wie H, Hero H and Solheim T 1998 Int. J. Oral Maxillofac. Implant. 13837

Wolke J G C, Vander Waerden J P C M, Schaeken H G and Jansen J A 2003 Biomaterials 242623

Xue W, Tao S, Liu X, Zheng X B and Ding C 2004 Biomaterials 25415

Yang C Y, Lin R M, Wang B C, Lee T M, Chang E, Hang Y S and Chen P Q 1997 J. Biomed. Mater. Res. 37335

Yang Y C and Chang E 2001 Biomaterials 221827

Yoshinari M, Ohshiro Y and Derand T 1994 Biomaterials 15529

Yunzhi Yang, Kyo-Han and Kim Joo L Ong 2005 Biomaterials 26327

Zeng H and Lacefield W R 2000 J. Biomed. Mater. Res. 50239 Zhang M Y and Cheng G J 2011 Nano Biosci. 10177

Zhang S, Wang Y S, Zeng X T, Cheng K, Qian M, Sun D E, Weng W J and Chia W Y 2007 Eng. Fract. Mech. 741884 